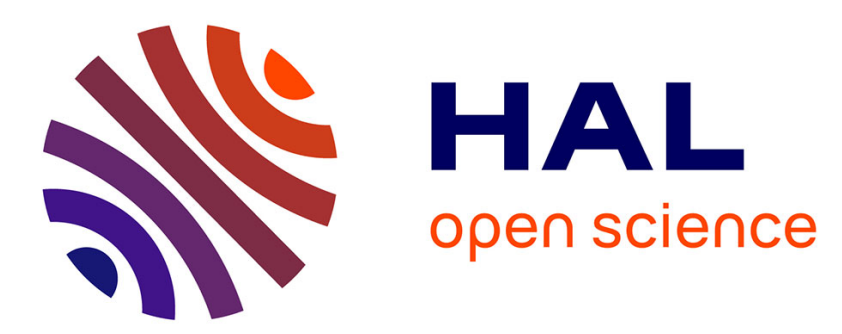

\title{
Logistic Information and Communication Systems (LICS) are Producing Organization Meanings
}

\author{
Nathalie Fabbe-Costes
}

\section{To cite this version:}

Nathalie Fabbe-Costes. Logistic Information and Communication Systems (LICS) are Producing Organization Meanings. International Conference on Systems, Man and Cybernetics, LAIL (École Centrale de Lille) (URA-CNRS 1440), Oct 1993, Le Touquet, France. pp.300-305. hal-01278256

\section{HAL Id: hal-01278256 https://hal.science/hal-01278256}

Submitted on 24 Feb 2016

HAL is a multi-disciplinary open access archive for the deposit and dissemination of scientific research documents, whether they are published or not. The documents may come from teaching and research institutions in France or abroad, or from public or private research centers.
L'archive ouverte pluridisciplinaire HAL, est destinée au dépôt et à la diffusion de documents scientifiques de niveau recherche, publiés ou non, émanant des établissements d'enseignement et de recherche français ou étrangers, des laboratoires publics ou privés. 
International Participation :

Algeria

Australia

Austria

Belgium

Brazil

Bulgaria

Canada

Czech Republic

China

Denmark

Egypt

England

France

Germany

Greece

Hong-Kong

Hungary

India

Ireland

Israel

Italy

Japan

Korea

Kuwait

Luxemburg

Mexico

Morocco

The Netherlands

Norway

Portugal

Poland

Romania

Russia

Finland

Scotland

Serbia

Singapore

Slovakia

South Africa

Spain

Sweden

Switzerland

Taiwan

Tunisia

U.A.E

U.S.A.

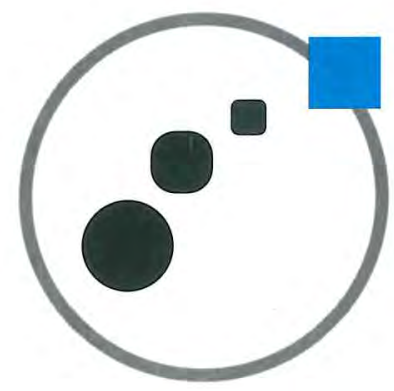

\section{3, International Conference on Systems, Man and Cybernetics}

Systems Engineering in the Service of Humans

Palais de l'Europe

Hôtel Westminster

Le Touquet - France

October 17 - 20, 1993 


\title{
Logistic Information and Communication Systems (LICS) are Producing Organization Meanings \\ 1993 IEEE Systems, Man and Cybernetics Conference Proceedings
}

\author{
Nathalie FABBE-COSTES \\ CRET (Faculty of Economics, Aix-Marseille II University) \\ Avenue Gaston Berger \\ F- 13625 AIX-en-Provence CEDEX 1
}

\begin{abstract}
Logistics is a management function in charge of physical flows inside and among companies. To succeed in its mission, it has to build information and communication systems that help to design networks, track freight and maintain organizations' efficiency. The purpose of this paper is to show that those logistic information and communication systems (LICS) are contributing towards producing organization meanings in companies. To ensure this contribution LICS must be considered as complex systems and designed as "knowledge-based management systems" building up and enriching collective knowledge concerning physical flows management. Therefore, the realization of LICS demands a transverse development approach, a global view of circulation and a broad management culture. It leads actually to imaging new methodologies that, according to the author, should help to imagine new collective way of managing physical flows and would succeed in developing global management models producing organization meanings in companies.
\end{abstract}

\section{INTRODUCTION}

To avoid any misunderstanding, this paper begins with a few definitions of logistics and points out the objectifs of this function (section II.A). Then it analyzes two main managerial characteristics of logistics that have great importance for information and knowledge management: logistics is a cross corporate management function (section II.B) and looks for global optimization among companies (section II.C).

These characteristics, combined with the need of permanent connection with physical flows, lead to particular demands vis-à-vis information and communication systems (Section III.A). Section III.B identifies why todays LICS don't give total satisfaction, and shows that this acknowledgment of failure will probably leads logistics managers and researchers to be creative. Section III.C indicates in what way LICS trying to reach teleological level in companies can produce organization meanings within and among companies.

As a conclusion, section IV specifies that logistics is not the unique managerial function that can undertake such innovative rethinking, but it seems that logistics is today the best reception for this kind of change.

\section{CHARACTERISTICS OF LOGISTICS MANAGEMENT}

\section{A. Logistics: objectives of the management function}

Because logistics is an up-to-date management word, often used with various meanings, we think it's worth to begin with a general presentation of this function.

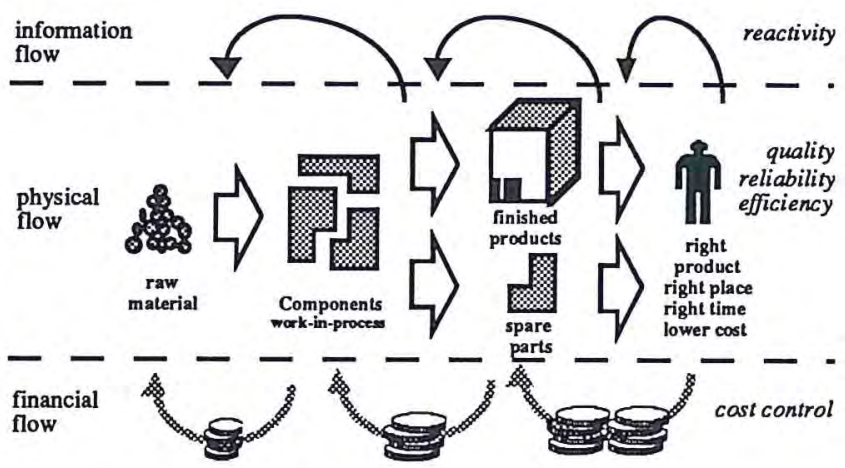

Fig. 1. What is logistics?

Logistics is often defined as the technology of control of physical flows (materials and goods) and related information that a firm sends, transfers and receives. 
More precisely, "logistics is the process of strategically managing the acquisition, movement and storage of materials, part and finished inventory from suppliers through the organization and its marketing channels, in such a way that current and future profitability is maximized through the cost-effective fulfillment of orders"[1]. In more general terms logistics consists in a global approach of the whole physical circulation: from raw material to components, to finished products sold to consumers and spare parts for products that have to be supported. It includes all information and financial flows associated to physical flows.

We could have chosen many others definitions. Some give a more technical view of this function (ex: logistics is how to get the right production at the right place, at the right time and with the lower total cost), others are only distribution oriented (ex: logistics is how to provide a profitable level of distribution services to customers through effective planning organizing and controlling of the move-store activities that facilitate production flow), some others only consider the strategic side of logistics (ex: logistics is a mean for supporting the firm's overall goal to achieve competitive advantage). [2]

The aim of logistics is to provide firms with global control of flows from downstream to upstream (ideally pulled by demand) and with global optimization of cost and level of service. Logistics is also supposed to provide firms with competitive advantages by: cost control upon the whole chain, quality and reliability of products and services, and reactivity to markets and demands. It is now considered as a strategic management function in firms [3].

To satisfy its ideal objectives of continuity (prevent stock-out) and fluidity (limit overcapacity), logistics has progressively gotten out of its original operational role that was made up of a combination of transport - handling - warehousing operations. Logistic is not only a technical project (physical circulation) but also a management project. Now logistics appears as an organizational approach that can conserve and improve the flexibility and reactivity of the firm vis-à-vis its environment. Logistic organization must be easily adaptable to the fluctuations and hazards of markets that are diversifying, changing and becoming international.

Logistics has now become very far-reaching with a "total" approach that is both transversal and very ambitious. With its role to synchronize overall physical flow, it is indeed in permanent interaction with all the classic functions of a firm and constitutes an active interface between the firm and its environment.

\section{B. Logistics: a transverse management function within companies}

Ideally, global logistics is a full management process downstream piloted which reconsiders the whole sourcingproduction-distribution system to ensure the consistency of physical circulation. It takes part in deciding who (makeor-buy choice), where (selection of plants and inventories' location), in what quantity (with definition of all stock levels), when and at what rates (scheduling) companies should deliver, produce and supply. It also intervenes in the design of products to optimize their life cycle cost improving their transportability and supportability at a good global price with a good associated service level. Therefore logistics is a transverse management function operating at strategic, organizational and technical levels within companies. Being officially in charge of all the planning coordination and control of the whole supply chain, logistics has obtained a status that enables it to negotiate with every function (marketing, manufacturing, finance, personnel...) to develop a really global management of its services.

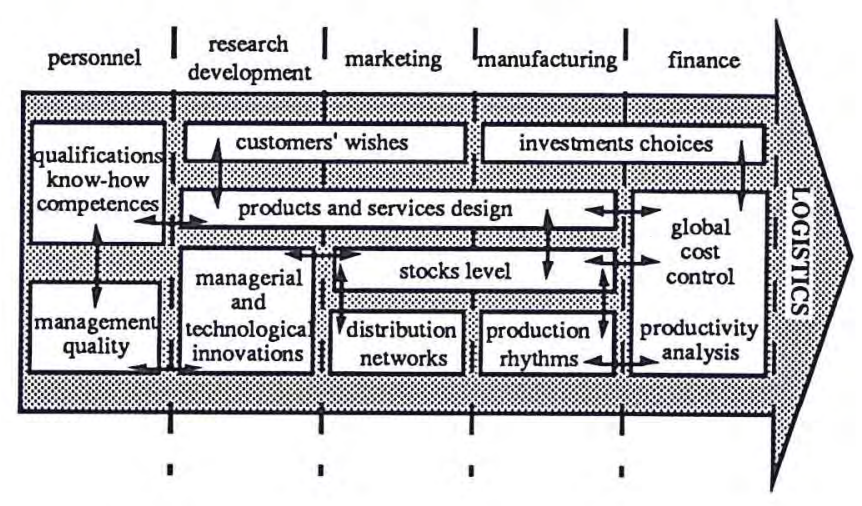

Fig. 2. Logistics : a transverse function

However, physical circulation is not (and must not be) the private field of logisticians. Many actors in the firm are concerned by the problem of physical flows management. Of course everyone will have its own interest (probably contradictory with some others), some people perhaps will have a narrow view of the problem, but everyone has a piece of logistic knowledge. Then, one purpose of logistics should be to constitute itself the place where to share (put in and take from) information about physical circulation (a kind of "thinks tank").

In fact, logistics plays much more than this "passive" role that is nevertheless very important and must not be undervalued. Being responsible for piloting flows, logistics has to know about each operation in the chain, makes 
them coordinated, helps them to be articulated and better synchronized, can possibly rearrange them to improve a global optimization of the chain. Because of this operational and organizational responsibility, logistics can contribute towards producing organization meanings to the multiple operations held in companies. This "active" role of logistics consists in helping every actor:

- to situate its action in the chain (how he is integrated in the process),

- to know about the constraints (not only those involved in its own decision-making process),

- to understand the effects of poor quality (errors, defects, delay..., how they propagate, what is level of over costs they generate...)

- and even to simulate impacts of certain decisions (participation in the decision-making process itself).

\section{Logistics: towards global coordination among companies}

Because the logistic chain pass through many companies (manufacturers, third party logistic companies, wholesalers, retailers, after-sales suppliers...), logistics management cannot be limited by corporations' borders. Collective optimization is indeed the objective of logistics [4]. All that have been said previously for a particular corporate logistics should then be achieved at the global chain level.

It is of course much more complex to reach

- because of the multiple actors implicated who have their own strategies,

- because the global optimization generally is not the sum of each firm's optimization,

- and because the global chain often doesn't have a unique pilot.

In fact, global logistics optimization can be considered as a good example of what is called "ecopiloting" [5]. This complexity has been increasing during the past ten years for two main reasons.

First reason, most companies in industries as diverse as manufacturing and grocery retailing have sought competitive advantage by concentrating on their core business. They often have decided to subcontract any logistics operation that is not considered as making part of their core business nor as strategic. This tendency has also been observed within the logistics and transportation industry. Third party logistics companies have progressively specialized and now subcontract operations they don't perform by themselves [6]. The result is that an increased number of companies intervenes in a logistic chain. Then coordination between all actors is both more necessary and more complex. It demandsa real (if not realtime) and effective communication to take in charge successfully the whole circulation.

Second reason, to face uncertainty, most manufacturers and retailers have tried both to decrease the level of stocks (towards zero-stock), to increase the variety of products (to meet customers' expectations) and to speed up their circulation (to respond more rapidly to any evolution of the demand). Such organizations (often called "just-in-time") are working with less security margins and any hazard occurring in a chain have a good chance to propagate up to the end-customer, all the more so rapidly that speed of circulation is higher. To avoid this, the design of logistic chains has to be rigorous, some back-up solutions must be also designed, and the communication network must permit to react rapidly to any abnormal situation.

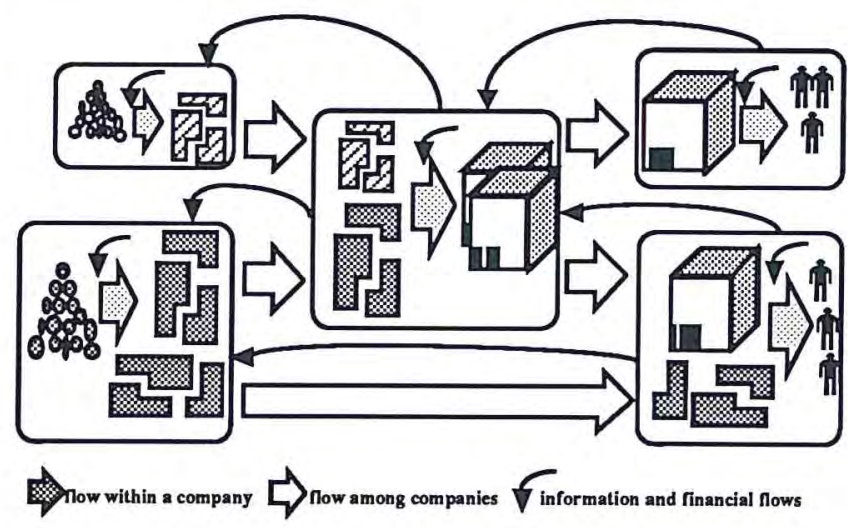

Fig. 3. Logistics : towards global coordination

\section{LICS: AN OPPORTUNITY TO PRODUCE ORGANIZATION MEANINGS IN COMPANIES}

\section{A. The need for LICS, how it supports logistics management}

The presentation of logistics shows that this function has to build a parallel information and communication system directly connected with physical circulation to help logisticians (at every level) to forecast plans organize and follow the operational process and react against any disruption. Because logistics is in charge of the whole physical chain management, LICS must at least "know" the physical possibilities among the potential players in the chain (both internal and external), inform everyone about the undertaken operational decisions, and be informed back of what is happening at each stage of the process (feedback information). Because technology has been 
greatly developing improving and disseminating, todays LICS can even follow in real time the circulation of goods and check all operations, routes and time. We are to show, further in this paper, that this characteristic of LICS represents a great opportunity for changing management process.

At a strategical level LICS must provide managers with adaptedand accurate logistic information indicating the results (speed, quality, cost...) of the chosen global logistic organization. This a posteriori control is very classic and important to verify quality of forecasts and effectiveness of organization. It is not sufficient to help managers to adapt organization. LICS should also participate in the watch process of companies and reach the teleological level of corporate management [7].

This idealistic view of LICS (compared with todays most frequent reality) highlights the importance of information in logistics management in particular to control physical flows, to take the "right" decisions at each management level and to provide adaptative information to managers.

It points out that:

- logistics is a complex activity that combines a wide range of techniques to handle just as well goods and information,

- the management of this complexity demandsa global understanding of the vital links between information technology and logistics management in a competitive business environment,

- logistics managers are the architects and conductors of a multi-technolgy system involving multi-competence personnel and they undertake cross-function decisions [8].

The confrontation with corporate reality shows a gap that, according to us, reveals more an organizational paradigm inadequation than a lack of technology investment.

\section{B. LICS: a potentially creative acknowledgment of failure}

Most companies have worked hard to build such LICS. Most of them have highly invested in important projects that include advanced technologies such as informatics, electronic data interchange, optical bar-coding identification of goods, automated handling equipment, computer integrated manufacturing, satellite vehicle localization and communication systems and so on [9].
But everyone admits that todays operational LICS don't really fit with logistics management requirements as previously defined. They are not so well integrated: logistics is divided into various modules (distribution, inventories, production, transportation, supplying...) that hardly communicate. In fact, many LICS had only been interfaced to old separated modules that weren't designed to share information. They don't guarantee the coordination between functions and actors and only achieve local optimizations. It is frequent to observe very sophisticated computerized sub-systems (for supplying, inventory, or production) that are mostly isolated. There are very few examples of multi-actors' optimization. EDI connections when they exist only serve to administrative exchanges such as orders, delivery advice, invoice and payment advice. Above all, todays LICS don't adapt easily to significative changes, either internal or external ones.

In fact, logistics managers consider they have reached the limits of traditional management models and above all feel they are confronted to the inadequacy of "classic" conceptions of organization. They are ready to be innovative and the problems raised by LICS' design are potentially rich of management innovation.

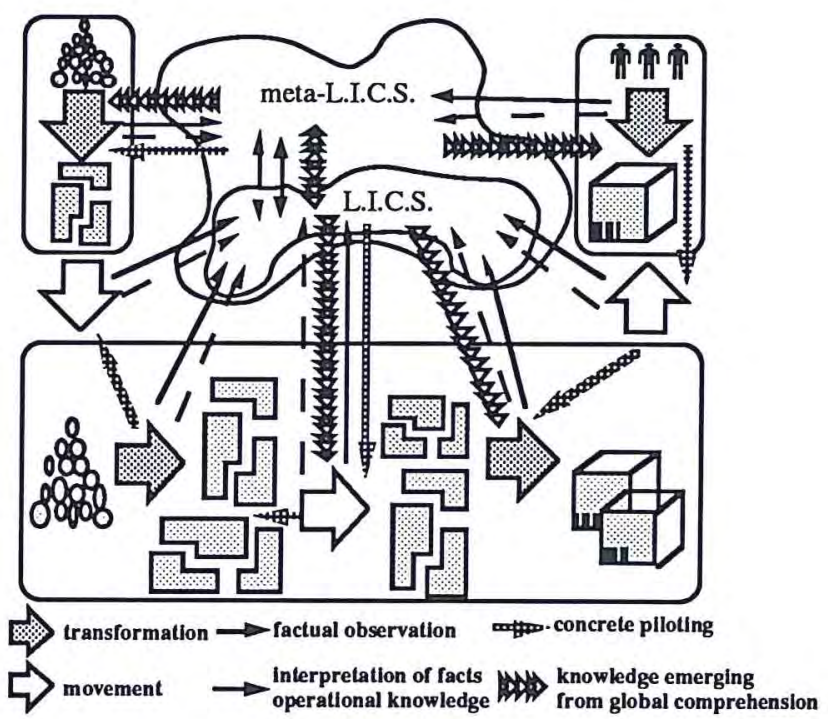

Fig. 4. LICS are producing organization meanings

What are the problems raised?

- LICS must be "fed" by every management function in the company. Each one is concerned by physical circulation, has information about it and has a specific point of view that can be interesting. The aim is to gather every piece of knowledge scattered in the company 
concerning physical flows, catching it if possible where it has been created. The problem is also to imagine a permanent connection with every source of knowledge, just because a firm is a living body and people's knowledge changes with it.

- In return, LICS should provide every function with informational added value. Because it capitalizes corporate collective knowledge on all "movements" produced, LICS should enrich corporate knowledge, in particular with the global view of the physical activity that logistics is the only one to possess.

- These knowledge functions (gather and add value) of LICS must be enlarged to all partners in the chain. LICS can't be restricted to one firm, because flows circulate between numerous companies. The first level is to enable a genuine coordination with external partners. The second one is to imagine common optimization systems (towards co-piloting circulation). This higher level supposes the creation of logistic informational networks between companies and will lead to the design of LICS networks. This means a new level in logistics and communication systems: from LICS to meta-LICS.

Design of LICS and meta-LICS sets numerous methodological problems in various fields that haven't yet been solved. Problems concern essentially knowledge engineering and LICS design. What kind of methodology should be used to collect logistics knowledge? How can an engineering to share knowledge between managerial functions be developed? What kind of representation should be used? What formalization? How can a collective (inside and between companies) knowledge concerning circulation be built? What kind of common models must be developed? What are the technologies that should be associated in LICS? How must the LICS and meta-LICS device be organized? What kind of systems networks?...

These questions are not specific to logistics, but today logistics is probably the unique function that does formulate them. These questions exactly lead to a renewal of organizational approachs and logistics is according to us able to contribute to construct innovative responses.

\section{How LICS are contributing towards producing organization meanings}

The necessary permanent contact with physical operations is an important characteristic of LICS and a great chance for logistics. Logistics being directly connected to physical flows declaresitself as the function of the movement, of the action, of the transformation. Because most models don't fit with global optimization, logistics has developed auto-observation. It doesn't mean that logistics is throwing out models previously developed, in particular operational research ones. It is only reconsidering their necessity and their combination in LICS with the knowledge built through experience.

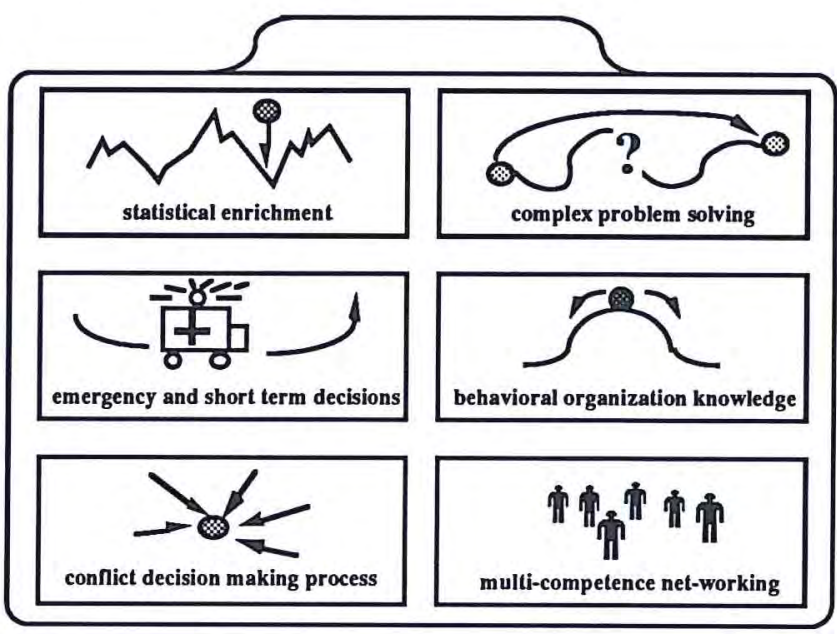

Fig. 5. LICS combine management tools

With the help of technology LICS has acquired and memorized important data bases of what happens in the chains it manages. But knowledge can't emerge from rough statistical series. Many other elements have to be taken in account, in particular special events, to evaluate and understand phenomena appearing as abnormal. Logistics is working on how enriching LICS' statistical data with other information that often can't be automatically acquired.

Beyond statistics, logistics is experimenting LICS improvement of managerial representation. Going with the action, logistics has been trying to formulate this action in "behavioral rules". Logistics is now getting in the learning stage, creating know-how from operation representation.

Emergency decisions (in front of hazards), accepted inexperience (in particular at the strategic level) leads also logistics to adopt short term decisional behavior, sometimes without knowing nor formulating the aim. Through logistics observation it could be possible to determine aim of dedicated organizations.

Logistics is a function that is almost permanently solving problems and tries to develop in LICS problem solving models. The control of a physical chain consists in solving the following problem: I know where I want to go, when I want to arrive and the price I want to pay, then what is the itinerary to chose knowing that it is in a limited rationality context (we don't speak of mathematical optimization!). 
Nature of logistics is to design adaptative and transitory organizations. Each logistic organization is an unstable equilibrium that will perhaps fail tomorrow and will have to be changed. Logistics competence probably lies in its capacity to adapt permanently plans to what is happening in corporate environment. This competence supposes a behavioral knowledge: how does organization react in front of external solicitations and internal evolution. LICS must represent the memory of what happened in environment, of how goods have been moved (the way) and history of decisions taken during this physical history. LICS must support a kind of "auto-representation" of activities.

But the dimension that appears the most interesting is probably the ecological one, it is to say the multiexperts network LICS can mobilize. LICS can settle a competence network shared by a number of logistics partners. LICS should be both open and protect to permit almost empirical data processing leading to collective innovative approaches. Logistics eco-piloting process and EDI technology in LICS should increase exchanges between actors and collective learning.

Globally, logistics tries to solve problems combining conflicting demands and objectives: organizational flexibility and control, standardization and customization of products and services, profits and ethics (in particular with network partners), broad generalist knowledge and specialist skills, management by control versus people's empowerment. Building LICS are in fact helping organization to operate a creative reflection about its managerial practices. Logistics forces to rethink: the environment for management, organizations, management itself, management teaching and learning, even research in management.

\section{IV- CONCLUSION}

\section{A. Logistics: an opportunity to reconsider management?}

Today, logistics is a function fully recognized in every company. It even appears in most organization chart. One could think that logistics is another one function like marketing of finance and that it's not so innovative! Of course it is possible to find example of such old-manner logistics, just juxtaposed, or worse a superadded to the existing ones. One could also say that money, or personnel are also transverse flows and that it is not a logistics characteristic. That is true, but those functions have developed themselves in a classic management context, and experiences show they hardly succeed in changing. Logistics could be an example for managing such flows and it probably will be.

The fact is that logistics is a recent function which from the beginning has claimed its transverse particularism, has adhered at the systemic movement, and is trying to create its own management philosophy. Most logistic managers and researchers are people really motivated by rethinking organizations but in a constructionnist manner. We could say in a familiar way that they are more interested in how they walk than where they are going. They don't want to refer systematically to existing models, but don't want systematically to reject them.

Logistics, because of its evolution, represents an opportunity to pilot changes in particular concerning organization. Logistics is a cross function management, develops knowledge in coordination and interfaces, and becomes a support of the corporate cognitive process. Logistics information and communication systems that support the physical organization seem to be the first piece of a new intelligent management system.

\section{B. LICS: a piece of intelligent management systems?}

LICS don't represent the entire management information system of a company. It is only the subsystem in charge of physical flows. But first this is a crucial part of many businesses and has great strategical impacts, second it is related to every part of business life: from ordering process to payment through personnel management production and investments. LICS are leading to new methodological approaches that will have impact on other information and communication sub-systems. LICS are probably the first stage of a more global change in information and communication management.

Beyond LICS design, the way LICS manage information is also important for business issues. If LICS provide a better (in the sense of adaptation, evolution) knowledge about circulation, it could help companies to find new management responses to face the complex and changing conditions of todays environment. Most companies are upset by "chaos" in business, perhaps because they use models that are no more adapted. All that is being developed in logistic domains could help every function to rethink their "professional rules" and decision making systems, in order to create more intelligent 
management systems, more knowledge-based than control-based.

We hope that logistics is to contribute with effectiveness to this process that should enrich management science.

Aix-en-Provence, Septembre 1993.

\section{REFERENCES}

[1] Logistics. The strategic issues, collective book edited by Martin CHRISTOPHER, Chapman \& Hall, London, U.K. 1992.

[2] We suggest to refer to La logistique, Hervé MATHE \& Daniel TIXIER, Coll. Que-sais-je?, PUF, Paris, 1987, to have a more detailed presentation of what is in concrete terms logistics.

[3] See "Formulating Logistics Strategy" chapter written by N. FABBE-COSTES \& J. COLIN, in Logistics and distribution planning : strategies for management, collective book coordinated par J. Cooper, Kogan Page, London, U.K, 1993.

[4] This level of coordination has been developed in "Synergie et compétitivité logistiques : le développement de l'échange automatique de données logistiques entre fabricants, distributeurs et opérateurs de transport", N. FABBE-COSTES, J. COLIN, communication in Proceedings of the 5 th World Conference on Transport Research, Yokohama, Japon, July 1989.

[5] We refer to a concept built within a collective research undertaken by the MCX 1 group, Le pilotage de l'entreprise éco-système complexe, Dossier MCX 1, Marie José AVENIER (ed), Grasce URA CNRS 935, Aixen-Provence, France, Avril 1992. To know more about logistics as an eco-piloting process, see "La logistique ou la gestion des flux acceptés dans leur complexité", $N$. FABBE-COSTES, communication in the seminar MCX (Complexity Modelling), organized by AFCET \& GRASCE/CNRS 935, Aix-en-Provence, France, 1992.

[6] To know more about these tendencies, refer to European logistics : markets, management and strategy, James COOPER, Michael BROWNE \& Melvyn PETERS, Blackwell Publishers, Oxford, UK, 1991.

[7] We refer to complex system modelling developed by Jean-Louis LE MOIGNE in particular in La théorie du système général, PUF, 2nd Ed., 1984, and "La modélisation des systèmes complexes, Dunod, 1990.

[8] MURPHY and POIST in "Skill requirements of seniorlevel logistician" (International Journal of Physical Distribution and Logistics Management, Vol. $21 \mathrm{~N}^{\circ} 3$, pp3-14) point out the great importance of broad based management skills, of interfacing skills and information and communication systems know-how.

[9] To have a more detailed view of technologies involved in LICS, refer to Advanced logistics and communication in road freight transport operations, collective research report of the TA1 Experts Group of OECD, OECD Ed., Paris, 1992. 